\title{
新时代我国生态文明区域协同发展战略研究
}

\author{
“生态文明建设若干战略问题研究 (三期)”综合组
}

摘要：本文是中国工程院重大咨询研究项目 “生态文明建设若干战略问题研究（三期）”综合成果, 文章评估了 2017 年我 国生态文明发展水平状况及动态变化, 以我国生态文明发展区域不平衡问题为重点, 选择东部地区、中部地区、西部生态脆 弱区及京津冀区域, 围绕大城市群环境一体化综合整治、重点开发区生态保护与绿色发展、生态脆弱区生态资源资产协同增 长以及先发地区生态产品价值实现等问题, 总结分析了我国生态文明发展的区域差异和突出问题, 提出我国生态文明区域协 调发展的战略与对策, 为国家新时代生态文明发展与建设的宏观决策提供战略建议。

关键词: 新时代; 生态文明; 区域协同; 京津冀; 中部地区; 东部地区; 西部生态脆弱区

中图分类号: X196 文献标识码: A

\section{Regional Coordinated Development of China's Ecological Civilization Progress in the New Era}

\author{
The Comprehensive Research Group for Research on Several Strategic Issues on Ecological \\ Civilization Construction
}

\begin{abstract}
Based on comprehensive research results of the major consulting project of the Chinese Academy of Engineering "Research on Several Issues on Ecological Civilization Construction (Phase III)", we evaluated the development level and dynamic changes of China's ecological civilization progress in 2017. Focusing on regional imbalance of ecological civilization development in China, we selected several typical areas as the research objects, including Eastern China, Central China, ecological fragile region in Western China, and the Beijing-Tianjin-Hebei region. We then summarized and analyzed the regional differences and prominent problems in the development of ecological civilization in China from the aspects of integrated and comprehensive improvement of urban agglomeration environment, ecological protection and green development of key zones for development, coordinated development of ecological resources and assets in ecological fragile regions, and value realization of ecological products in developed regions. Furthermore, relevant countermeasures and strategy for the coordinated development of ecological civilization in China is proposed, thus to provide strategic suggestions for the macro decision-making of the development of ecological civilization in China in the new era.

Keywords: new era; ecological civilization; regional coordination; Beijing-Tianjin-Hebei urban agglomeration; Central China; Eastern China; ecological fragile region in Western China
\end{abstract}

收稿日期 : 2019-09-15; 修回日期 : 2019-09-20

联系人：宝明涛, E-mail: bmt@cae.cn

资助项目：中国工程院咨询项目 “生态文明建设若干战略问题研究（三期）” (2017-ZD-09)

本刊网址：www.engineering.org.cn/ch/journal/sscae 


\section{一、前言}

生态文明建设是关系中华民族永续发展的根 本大计。党的 “十八大” 以来, 我们不断探索研究 生态社会建设与消费理念相渗透、生态工业建设与 城镇生态相融合、生态农业建设与乡村生态相协调 的生态文明建设路径, 聚焦研究资源环境承载力与 经济社会发展布局和固体废物分类资源化利用等战 略 $[1,2]$ 。党的 “十九大” 后, 我国生态文明建设 进入新时代，生态文明理念深入人心，我国生态 文明建设进入了快车道，取得了前所未有的历史性 成就 [3]。但城乡生态文明发展不平衡、区域生态 文明发展不平衡、经济发展与生态保护不平衡等生 态文明建设不平衡问题依然突出。本研究在前期研 究的基础上，以区域性问题为重点，围绕 “十三五” 时期京津冀协同发展, 中部崛起, 西部生态安全屏 障建设和国家生态文明试验区建设等战略需求，从 区域、省域、市域、县域等不同的尺度选择典型地 区, 开展生态文明区域协同发展战略研究。研究重 点从整体上梳理我国生态文明的发展成效，从区域 上找准生态文明建设的差异与问题，以区域协同为 突破口提出我国生态文明发展战略与对策，对贯彻 新发展理念、调整经济结构、推动经济绿色发展、 改善生态环境、持续推动生态文明建设具有重要的 战略意义。

\section{二、新时代我国生态文明建设的成效}

为客观反映我国生态文明建设取得的成绩，准
确量化我国生态文明的发展态势，课题组完善了二 期项目研究构建的中国生态文明指数的指标体系、 基准与评估方法等 [4,5], 评估了 2017 年我国生态 文明发展水平，分析了 2015-2017 年期间的年际 变化。

\section{（一）我国生态文明发展水平整体接近良好水平}

2017 年我国生态文明指数得分为 69.96 分，达 到优秀或良好水平的城市总数为 179 个, 占所有 评估城市总数的比例超过 $55 \%$ ，约占国土面积的 $44 \%$ 。在所有评估城市中, 属于优秀 (A)、良好 (B)、 一般 (C)、较差 (D) 等级的城市个数占比分别为 $0.62 \% 、 54.46 \% 、 42.46 \%$ 和 $2.46 \%$ （见表 1 ）。福建 省、浙江省和重庆市在省（市）中位列前三，排名 前十的城市依次为厦门市、杭州市、珠海市、广州 市、长沙市、三亚市、惠州市、海口市、黄山市和 大连市，平均得分达到 78.47 分。

\section{（二）我国生态文明建设提质增效成果显著}

与 2015 年相比, 2017 年我国生态文明指数得 分提升了 2.98 分, 37 个城市生态文明指数显著上 升，198 个城市生态文明指数明显上升，全国约六 成国土生态文明水平取得明显提升（见表 2)。两年 期间，在经济社会快速发展的同时，环境质量得到 持续改善。人均国内生产总值（GDP）年平均增长 $6.2 \%$, 为中国生态文明指数的增长贡献了 0.19 分; 空气质量指数 (AQI) 和城市水质指数 (CWQI) 平均下降 $11 \%$ 和 $20 \%$, 分别为中国生态文明指数 的增长贡献了 0.53 分和 0.48 分。

表 12017 年中国生态文明指数等级情况

\begin{tabular}{cccc}
\hline 生态文明指数等级 & 城市个数 / 个 & 得分均值 / 分 & 比例 /\% \\
\hline A & 2 & 80.47 & 0.62 \\
B & 177 & 73.34 & 54.46 \\
C & 138 & 66.16 & 42.46 \\
D & 8 & 58.09 & 2.46 \\
\hline
\end{tabular}

表 22015 年、2017 年中国生态文明指数等级及变化情况

\begin{tabular}{cccc}
\hline 生态文明指数等级 & 2015 年城市个数 $/$ 个 & 2017 年城市个数 $/$ 个 & 城市数量变化 $/$ 个 \\
\hline A & 0 & 2 & 2 \\
B & 105 & 177 & 72 \\
C & 192 & 138 & -54 \\
D & 28 & 8 & -20 \\
\hline
\end{tabular}




\section{（三）我国生态文明的突出短板得到明显缓解}

损害群众健康的突出环境问题得到缓解, 环 境质量指数未达标城市占比由 2015 年的 $18 \%$ 下降 到 2017 年的 $9 \%$, 环境空气质量与地表水环境质量 的提升分数大于 5 分的城市分别有 157 个和 89 个。 重点区域的环境质量明显好转, 生态文明指数提升 最快的北京市增加了 7.54 分, 环境质量改善为生态 文明指数的增长贡献了 6.38 分。经济发展与生态环 境保护不协调的问题得到缓解, 环境质量指数与产 业优化指数同步提升的城市达到 142 个, 占所有评 估城市总数的比例超过 $43 \%$ 。

\section{三、我国生态文明发展区域差异与问题}

我国东部、中部、西部的生态文明指数依次为 71.17 分、69.91 分和 68.98 分。优秀及良好水平的 城市主要集中分布在皖、浙、闽、粤地区, 一般水 平的城市分布较分散, 较差水平的城市则在华北、 西北地区较为集中。东部地区约有 $62 \%$ 的城市达 到良好及优秀水平, 中部地区和西部地区无优秀水 平的城市, 良好水平的城市分别为 $59 \%$ 和 $46 \%$ （见 表 3)。这表明, 区域发展不协调、经济与生态环境 发展不均衡仍然是我国生态文明发展的突出问题。

\section{（一）东部地区生态保护与经济发展不协调}

东部地区是我国经济相对发达的地区, 生态 文明发展建设水平与中部、西部相比也相对较高。 2017 年东部地区生态文明指数平均得分为 71.17 分, 属于良好水平，2015-2017 年生态文明指数得分提 高了 2.95 分。 2 个城市达到优秀水平, 61 个城市达 到良好水平, 38 个城市为一般水平, 仅 1 个城市为
较差，分别占城市总数的 $1.96 \% 、 59.80 \% 、 37.26 \%$ 和 $0.98 \%$ 。但是东部地区的经济发展和生态保 护不协调, 绿色生产得分为 71.47 分, 比中部高 3.38 分, 比西部高 4.03 分; 东部地区绿色环境得 分为 67.85 分, 比中部低 2.1 分, 比西部低 2.92 分; 东部地区绿色环境与绿色生产得分相差 3.62 分, 远高于中部和西部; 城乡发展不平衡表现为城乡 居民收入比为 2.03 , 比中部高 0.17 , 比西部低 0.64 , 城市居民人均可支配收入为农村居民人均可支配 收入的两倍。东部地区作为我国的优先发展地区 在发展过程中付出了一定的资源环境代价, 有些 地区还存在先污染后治理的现象。未来应持续优 化产业结构、提高资源环境利用效率、加大污染 治理的力度、促进生态产品价值实现。

\section{（二）中部地区面临生态保护与经济发展双重压力}

中部地区在全国区域发展格局中具有重要战略 地位, 是我国粮食生产基地、能源原材料基地、现 代装备制造及高技术产业基地和综合交通运输枢 纽 [6], 是我国现代农业发展核心区、全国新型城 镇化重点区。2017 年中部地区生态文明指数平均 得分为 69.91 分, 属于一般水平, 2015-2017 年生 态文明指数得分提高了 2.78 分。无城市达到优秀水 平, 61 个城市达到良好水平, 39 个城市为一般水平, 3 个城市为较差，分别占城市总数的 $59.22 \%$ 、 $37.86 \%$ 和 $2.92 \%$ 。但是中部地区仍然面临产业整体 结构不合理和三次产业内部结构效益不高的问题, 轻重工业比例失调, 资源开采粗放, 生态破坏严重。 第三产业增加值占 GDP 比重仅为 $43 \%$, 比东部低 $4 \%$, 绿色环境得分为 69.95 分, 比东部高 2.1 分, 比 西部低 0.82 分。中部地区仍处于工业化中后期阶段,

表 3 东中西部地区生态文明指数评估结果

\begin{tabular}{|c|c|c|c|c|c|c|c|c|c|c|c|}
\hline \multicolumn{4}{|c|}{ 东部 } & \multicolumn{4}{|c|}{ 中部 } & \multicolumn{4}{|c|}{ 西部 } \\
\hline 领域 & 得分 & 指数 & 得分 & 领域 & 得分 & 指数 & 得分 & 领域 & 得分 & 指数 & 得分 \\
\hline \multirow[t]{2}{*}{ 绿色环境 } & 67.85 & 生态状况 & 60.56 & 绿色环境 & 69.95 & 生态状况 & 65.20 & 绿色环境 & 70.77 & 生态状况 & 56.93 \\
\hline & & 环境质量 & 72.71 & & & 环境质量 & 73.12 & & & 环境质量 & 80.00 \\
\hline \multirow[t]{2}{*}{ 绿色生产 } & 71.47 & 产业优化 & 71.78 & 绿色生产 & 68.09 & 产业优化 & 65.78 & 绿色生产 & 67.44 & 产业优化 & 65.48 \\
\hline & & 产业效率 & 71.02 & & & 产业效率 & 71.54 & & & 产业效率 & 70.38 \\
\hline \multirow[t]{2}{*}{ 绿色生活 } & 69.20 & 城乡协调 & 67.84 & 绿色生活 & 66.14 & 城乡协调 & 64.84 & 绿色生活 & 61.62 & 城乡协调 & 59.22 \\
\hline & & 城镇人居 & 70.82 & & & 城镇人居 & 67.69 & & & 城镇人居 & 64.40 \\
\hline \multirow[t]{2}{*}{ 绿色设施 } & 79.64 & 污染治理 & 95.88 & 绿色设施 & 77.56 & 污染治理 & 95.16 & 绿色设施 & 76.81 & 污染治理 & 92.25 \\
\hline & & 自然保护 & 47.56 & & & 自然保护 & 46.38 & & & 自然保护 & 51.68 \\
\hline
\end{tabular}


对资源、劳动力要素和投资驱动依赖较重, 产业升 级、动能转换等难度更大。未来应着力聚焦高质量 发展, 平衡好在 “保护中发展” 和在 “发展中保护” 的关系。

\section{（三）西部地区生态安全与脱贫攻坚迫在眉睫}

西部地区是我国重要的生态屏障区，承载着水 源涵养、防风固沙和生物多样性保护等重要生态功 能, 是我国主要的集中连片贫困地区、少数民族人 口集聚区。这些区域为了维护民族团结和稳固边疆 需要加快经济发展, 面临着既要保护 “绿水青山” 又要创造 “金山银山” 的双重任务, 协调保护和发 展难度较大。2017 年西部地区生态文明发展指数平 均得分为 68.98 分, 属于一般水平，2015-2017 年 生态文明指数得分提高了 3.17 分。无城市达到优秀 水平, 55 个城市达到良好水平, 61 个城市为一般水平, 4 个城市为较差，分别占评估城市总数的 $45.83 \%$ 、 50.83\% 和 3.34\%。西部地区基础设施和公共服务设 施滞后, 绿色设施得分为 76.81 分, 比东部低 2.83 分, 城乡发展极不平衡, 城乡居民收入比高达 2.67 , 比 东部和中部分别高 0.64 和 0.17 , 城市居民人均可支 配收入约为农村居民人均可支配收入的 3 倍。西部 地区自然生态环境脆弱，经济社会欠发达造成生态 文明发展水平相对滞后。未来应加大污染治理和交 通运输等基础设施建设, 大力发展旅游文化产业, 进一步巩固脱贫成果，不断提高生态文明发展水平。

\section{（四）京津冀地区区域、城乡生态文明发展双重不 均衡}

京津冀地区是世界级城市群、区域整体协同发 展改革引领区、全国创新驱动经济增长新引擎、生 态修复环境改善示范区。2017 年京津冀地区生态文 明指数得分为 64.83 分，2015-2017 年生态文明指 数得分提高了 4.28 分, 其中北京市生态文明指数涨 幅排名全国第一，两年间提高了 7.54 分，主要原 因是大气和水环境质量指标得分分别提高了 15.84 分和 14.53 分。但是京津冀高污染区域呈现排放物 强度大、环境复合污染突出等问题, 治理技术与发 达国家存在较大差距, 综合治理难度大, 河北产业 效率指数得分仅为 59.76 分。同时，京津冀地区城 乡发展差距较大, 区域整体发展不佳, 对整个区域 生态环境的改善带来一定的困难，北京、天津、河
北城乡协调指数得分分别为 72.61 分、 74.06 分和 60.57 分, 河北城乡发展差距高于北京和天津。京 津冀地区应强化实施一体化战略，通过体制机制创 新破解区域、城乡生态文明发展的双重不均衡。

\section{四、生态文明区域协同发展战略}

\section{（一）总体目标}

紧密围绕生态文明建设和国家经济发展战略, 以实现人民对美好生活的向往为目标, 坚持绿色引 领, 推动形成绿色生产方式和生活方式; 使绿色低 碳成为我国社会经济发展的强大引擎, 实现人民群 众物质生活水平和生态资源资产的双重富裕。

到 2035 年，全面实现经济发展与生态资源资 产双增长, 人均 GDP 将达到 2 万美元, 生态资源 资产总量比 2015 年提高 $35 \%$ ，形成低碳、无毒、 少废社会, 生态产业成为经济发展的强大引擎; 到 2050 年, 基本实现物质财富与生态福祉的双重 富裕, 达到中等发达国家水平, 人均 GDP 将达到 3 万美元，生态资源资产总量比 2015 年提高 $50 \%$; 基本形成零碳排放的 “无废社会”，全面建成反映 新时代中国特色社会主义特征的 “美丽中国”, 为 世界可持续发展提供“中国样板”。

\section{（二）基本原则}

坚持共生发展，保障人民群众在拥有高度富裕 物质生活的同时拥有高度优质的生态产品; 坚持和 谐共赢，以带动城乡、产业、区域协同增长与和谐 共赢为宗旨, 促进经济增长、生态保护和社会福祉 的协调发展; 坚持碳素平衡原则, 促进在生产过程 中碳排放被自然生态系统完全吸收, 实现碳素平衡; 坚持无废循环, 引导生产过程实现全元素闭环循环 的发展体系, 基本不向自然排放废弃物; 坚持双侧 发力, 从培育绿色需求市场与生态产品供给两个方 向使力, 形成完善的市场机制。

\section{（三）战略思路}

一是主体功能驱动促进均衡发展。以主体功能 定位确定分区发展方向, 利用东部沿海地区的经济 先发优势辐射带动中西部发展, 发挥中部承东启西 的区位优势和农业优势, 强化西部生态保护与建设 作为生态资产的战略储备基地; 健全城市反哺农 
村、工业反哺农业的机制, 促进城乡经济社会一体 化发展; 加大环境保护与生态建设投入力度, 促进 经济社会可持续发展。

二是市场驱动培育生态产业新业态。市场是经 济发展的基础, 只有通过消费市场拉动才能调动企 业发展积极性; 当前公众对优美生态环境的需求日 益强烈、消费方式正逐步转换与升级, 可以创造出 巨大的政策和市场需求, 形成社会经济发展的强大 绿色引擎, 推动经济生产方式绿色化, 构建科技含 量高、资源消耗低、环境污染少的绿色业态, 提升 自然生态系统服务供给能力。

三是创新驱动支撑高质量发展。以绿色科学技 术的群体性突破引领生态环境、资源能源利用效率 实现革命性的提升, 促进传统产业的绿色改造提升; 实现绿色基础研究与应用研究、技术开发协作贯通, 原始创新与再创新、集成创新融合迸发, 促进绿色 科技创新及时转化为生产力, 推动新技术、新产业、 新业态和新模式的融合创新和跨界发展, 为高质量 发展提供源源不断的动力。

四是制度驱动保障区域协同发展。同步推进财 税、金融、价格、投融资改革; 进一步完善公平公 正并存的市场主体激励约束机制、奖惩分明的政府 责权利机制和依法保护治理机制, 构建系统完备、 科学规范、运行高效、以人为本的制度体系, 使制 度成为区域协同发展的有力保障。

\section{（四）对策建议}

1. 持续推动大城市群跨区域环境治理, 创新体 制机制

跨区域协同发展涉及不同地方政府、不同部门 等, 建议建立大城市群生态建设和环境保护协调机 制, 尽快制定区域环境污染防治条例, 积极实施区 域大气污染联防联控技术; 建立跨区域环境保护合 作机制与环境联合监察执法工作制度, 提升区域环 境监测预警与应急能力; 优化监测统计体系, 形成 覆盖全部县域的区域生态环境质量监测体系, 并定 期开展统计监测工作, 实现县域生态文明指数评估。

2. 强化重点生态功能区生态产品价值实现, 助 力脱贫攻坚

在遵循自然生态规律的基础上对自然保护地进 行科学管护, 实现生态效益与经济效益; 以 “山水 林田湖草” 系统工程为依托, 统筹实施生态修复与
治理工程, 巩固提高生态产品供给能力; 制定生态 保护红线区生态产品价值实现策略, 在保障生态产 品供给能力稳步提升的基础上, 使生态产品生产者 和保护者获得收益, 构建农户可持续生计发展能力 以实现脱贫; 加大贫困地区基础设施建设, 促进生 态产品价值实现, 缩短城乡区域发展差距 [7]。

3. 找准自身特点, 深入推进重点开发区产业生 态化发展之路

重点开发区在经济发展过程中应牢牢把握住生 态红线底线不动摇、在环境容量允许范围内发展; 集中力量破解大气、水环境以及土壤污染等关键生 态环境问题和经济发展转型升级等突出重点问题, 统筹资源利用与环境保护, 统筹产业布局与生态功 能保护的问题; 产业发展要以绿色为标准, 着力推 进产业绿色转型升级, 支持大力发展节能环保、优 势特色农林产业, 绿色生态旅游业, 形成新的绿色 经济增长点, 强化节能减排, 促进经济低碳发展; 选择基于特色产业、生物质、水环境及资源型经济 转型为抓手的生态文明建设模式, 带动区域整体发 展; 根据地域特点分别制定加速新兴产业发展、生 物质能源优化发展、水环境保护以及资源型经济转 型等相关发展规划, 深入贯彻 “保护中发展” 的指 导思想。

4. 构建确保生态资源资产协同增长的西部生态 脆弱贫困区发展策略

加快建成西部生态屏障保护制度体系, 形成以 国家公园为主体的西部生态屏障保护体系; 强化生 态修复促进生态资产正增长, 深入实施各类重点生 态修复工程, 完善生态修复投入机制, 加强生态资 产用途管制; 积极探索建立西部绿色低碳循环产业 体系, 发展特色优势绿色农牧业与生态旅游业, 保 护性开发利用矿产资源, 发展循环工业, 探索西部 碳汇产业; 建立统一集中的国家生态补偿专项基 金, 研究将环境保护税扩展用于生态补偿专项基金, 按比例提取重点开发区、优化开发区土地出让金, 探讨发行生态彩票、生态债券、生态损害保险等资 金筹集方式, 扩大生态补偿专项基金渠道。综合考 虑各地生态保护、民生改善、公共服务的需求, 确 定各县区生态补偿资金额度并编制生态产品生产保 障供给规划及预算, 通过生态产品许可证交易的方 式使农牧民的收入与土地生态质量挂钩, 调动农户 主动开展生态保护的积极性。 


\section{五、结语}

“生态文明建设若干战略问题研究 (三期)”重 大咨询研究项目紧紧围绕 “十三五” 期间典型地区 的生态文明建设战略需求, 从多个尺度开展案例研 究与实践分析，提出新时代我国生态文明区域协同 发展的战略与对策, 对于促进我国生态文明建设具 有重要意义。

当前, 我国生态文明建设正处于压力叠加、负 重前行的关键期, 已进入提供更多优质生态产品以 满足人民日益增长的优美生态环境需要的攻坚期, 也到了有条件有能力解决生态环境突出问题的窗口 期。我们应该清醒地看到, 我国生态文明建设突出 短板依然存在，环境质量、产业效率、城乡协调等 主要生态文明指标与发达国家相比还有较大差距。

项目组将继续长期、稳定和深入跟踪我国生态 文明建设最新进展, 在绿色低碳循环发展上持续发 力, 在走新型工业化、新型城镇化、生态化智慧农 业道路上持续发力, 在培育绿色发展新动能、加强 绿色消费与文化教育、加快建立健全生态文明建设 五大体系上持续发力, 适时开展长江经济带以及黄 河流域生态文明建设若干战略问题研究, 为我国生 态文明建设提供新观点、新认识和新办法。

\section{参考文献}

[1] 生态文明建设若干战略研究综合组. 生态文明建设若干战略研 究 [J]. 中国工程科学, 2015, 17(8): 1-7.

The Comprehensive Research Group for Research on Several Strategic Issues on Eco-Civilization Construction. Research on several strategic issues on eco-civilization construction [J]. Study of CAE, 2015, 17(8): $1-7$.

[2] “生态文明建设若干战略问题研究 (二期) ”综合组. 生态文明 建设若干战略问题研究 [J]. 中国工程科学, 2017, 19(4): 1-5.

The Comprehensive Research Group for Research on Several Strategic Issues on Eco-Civilization Construction. Research on several strategic issues on eco-civilization construction [J]. Study of CAE, 2017, 19(4): 1-5.

[3] 习近平. 决胜全面建成小康社会 夺取新时代中国特色社会主义 伟大胜利 [R]. 北京: 中国共产党第十九次全国代表大会, 2018 .

Xi J P. To finish building a moderately prosperous society, to win the great victory of socialism with Chinese characteristics in the new era [R]. Beijing: The 19th National Congress of the Communist Party of China, 2018.

[4] 解钰茜, 张林波, 罗上华, 等. 基于双目标渐进法的中国省域 生态文明发展水平评估研究 [J]. 中国工程科学, 2017, 19(4): 60-66.

Xie Y X, Zhang L B, Luo S H, et al. Evaluating the level of provincial ecological civilization development in China using the double-benchmark progressive method [J]. Strategic Study of CAE, 2017, 19(4): 60-66.

[5] 舒俭民, 张林波. 国家生态文明指标体系研究与评估 [M]. 北京: 科学出版社, 2019 .

Shu J M, Zhang L B. Research and evaluation of national ecological civilization index system [M]. Beijing: China Science Publishing \& Media Ltd (CSPM), 2019.

[6] 中华人民共和国国务院. 国务院关于促进中部地区崛起 “十三五”规划的批复 [R]. 北京: 中华人民共和国国务院, 2016.

State Council of the PRC. Reply of the State Council on the "13th Five Year" plan for promoting the rise of the central region [R]. Beijing: State Council of the PRC, 2016.

[7] 张林波, 虞慧怡, 李岱青, 等. 生态产品内涵与其价值实现途径 [J]. 农业机械学报, 2019, 50(6): 173-183.

Zhang L B, Yu H Y, Li D Q, et al. Connotation and value implementation mechanism of ecological products [J]. Transactions of the Chinese Society for Agricultural Machinery, 2019, 50(6): 173-183. 